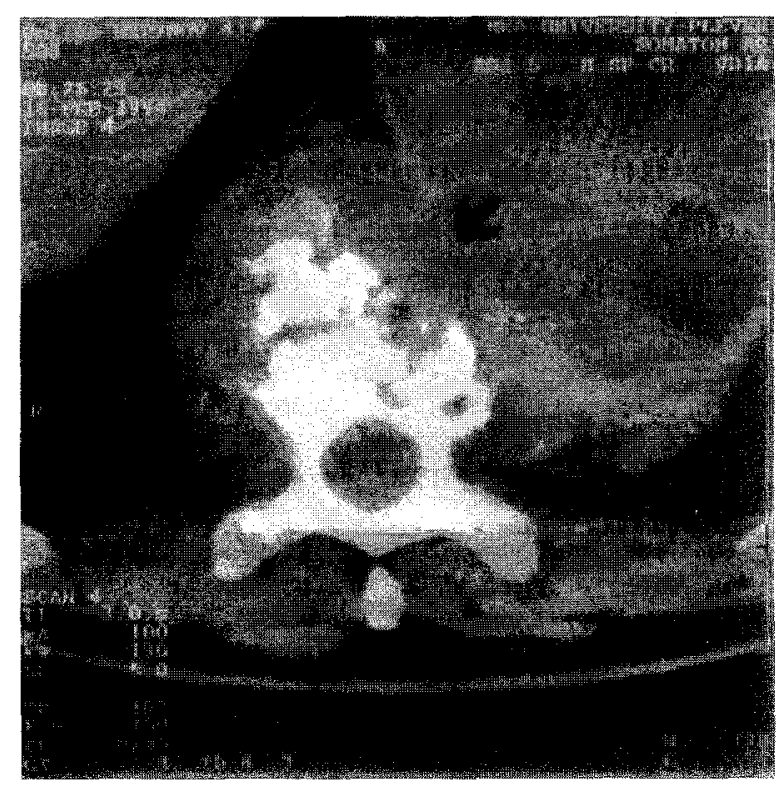

Fig. 2. Dilation of aorta and degeneration of thoracic vertebrae 9 and 10 revealed on computed axial tomography. Arrow indicates free bone sequesters of vertebrae and its deteriorated image. patients with false aneurysm located in the thoracic aorta and associated with dense adhesions and atelectasis of the left lung. A thorough history should be taken, with special attention to previous contact with animals. Serologic investigations should include not only tests for syphilis and acquired immunodeficiency syndrome but reaction to passive hemaglutination, immunoffuorescence assay, and enzyme-linked immunosorbent assay, tests specific for echinococcosis.

The absence of eosinophilia and other clinical manifestations of parasitic infection in our patient misled us to preclude the presence of hydatid cyst. Fortunately, our patient did not show any symptoms of recurrent or residual hydatid disease at 14 -month follow-up.

\section{REFERENCES}

1. Burkhardt F, editor. Mikrobiologische diagnostik. Stuttgart, Germany: Thieme, 1992:547-8.

2. Hendaoui L, Siala M, Fourati A, Thameur MH, Hamza R. Case report: hydatid cyst of the aorta. Clin Radiol 1991;43: 423-5.

3. Levicharov P, Drenovski V, Vassiley I, Markov Y. False aneurysm of the thoracic aorta caused by a hydatic cyst: a case report. Balas P, editor. Progress in angiology, Torino, Italy: Edizione Minerva Medica, 1985:381-3.

\title{
BENEFICIAL EFFECT OF SYNTHETIC HUMAN ATRIAL NATRIURETIC POLYPEPTIDE ON RENAL FUNCTION IN A PATIENT WITH GIANT ATRIA
}

Kazunobu Nishimura, MD, PhD, Katsuhiko Matsuda, MD, PhD, Satoshi Konno, MD, Akihiro Sugimoto, MD, Takaaki Koshiji, MD, Tadashi Ikeda, MD, Shinichi Nomoto, MD, PhD, and Toshihiko Ban, MD, PhD, Kyoto, Japan

The atrium has specific granules that contain atrial natriuretic polypeptides (ANP), which are secreted from the heart and circulate throughout the body as a hormone. The main pharmacologic properties of ANP are natriuresis, diuresis, vasorelaxation, and inhibition of aldosterone. ${ }^{1}$ Synthetic ANP is currently available and provides beneficial effects in patients with heart failure. In this

From the Department of Cardiovascular Surgery, Kyoto University Faculty of Medicine, Kyoto, Japan.

Received for publication July 26, 1996; accepted for publication Sept. 16, 1996.

Address for reprints: Kazunobu Nishimura, MD, PhD, Department of Cardiovascular Surgery, Kyoto University Faculty of Medicine, Kyoto, 606, Japan.

J Thorac Cardiovasc Surg 1997;113:793-5

Copyright (c) 1997 by Mosby-Year Book, Inc.

$0022-5223 / 97 \$ 5.00+0 \quad \mathbf{1 2 / 5 4 / 7 8 0 3 4}$ paper, the case of a patient with giant atria lacking ANP is described. The effect of synthetic ANP infusion is reported.

Case report. A 55-year-old woman was transferred to our department because of orthopnea and hepatocardiomegaly caused by mitral stenosis and tricuspid regurgitation. She has twice previously undergone mitral operation (closed mitral commissurotomy at age 21 years and open mitral commissurotomy at age 23 years), and congestive heart failure had developed because of recurrent mitral stenosis combined with severe tricuspid regurgitation that caused marked enlargement of both the left and right atria. The left atrium measured $73 \mathrm{~mm}$ according to the echocardiogram. The plasma concentration of ANP was less than the detectable value $(<5.0 \mathrm{pg} / \mathrm{ml}$; normal range, 8 to 32$)$ whereas that of aldosterone was extraordinarily high $(1731 \mathrm{pg} / \mathrm{ml}$; normal range, 57 to 161). Renal function was within normal limits with a $0.9 \mathrm{ml} / \mathrm{dl}$ creatinine level.

We first used femorofemoral cardiopulmonary bypass (CPB) and approached the heart through a right thora- 

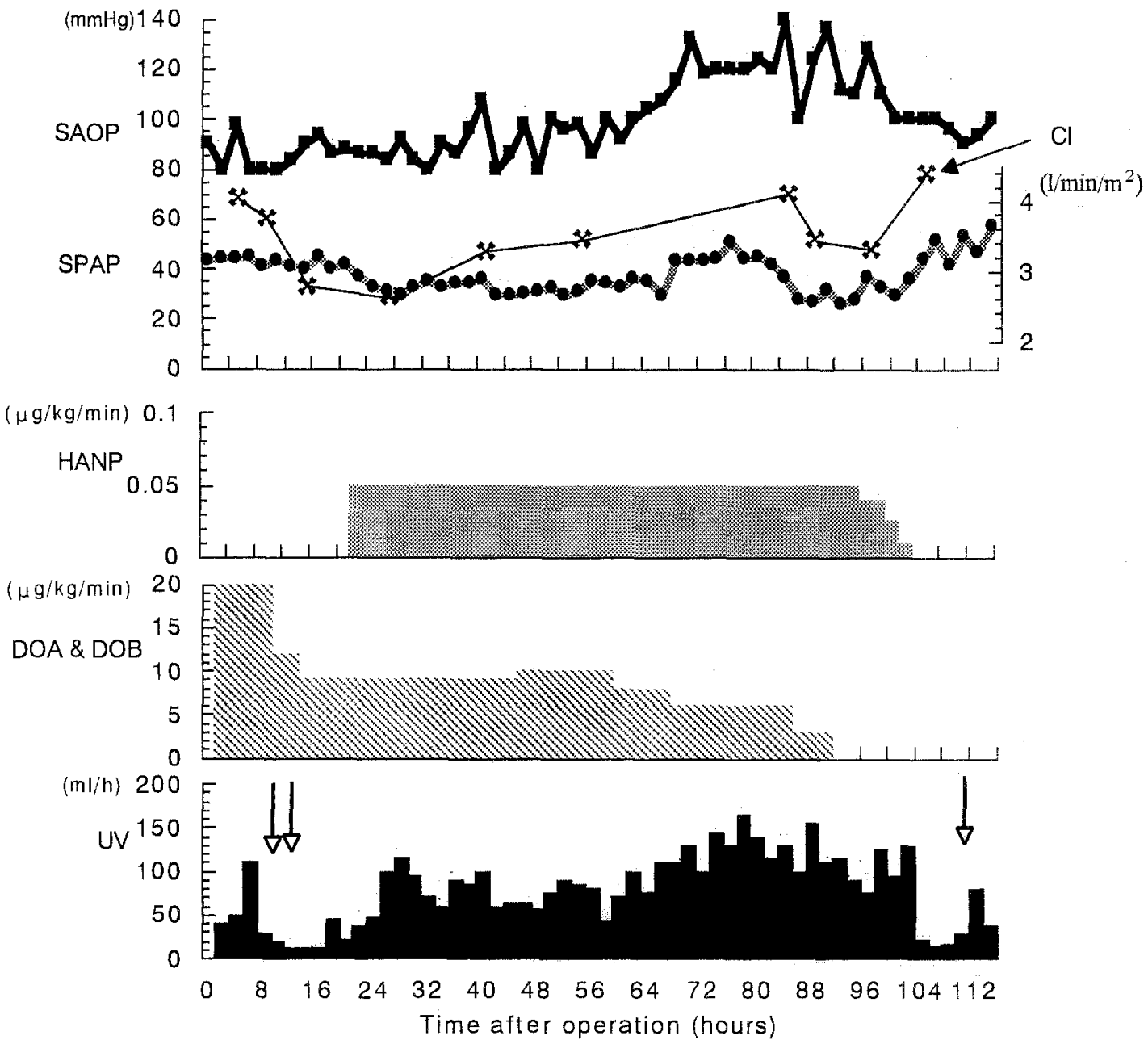

Fig. 1. Postoperative course showing hemodynamics, doses of human ANP $(H A N P)$ and catecholamine, and urine volume $(U \mathrm{~V})$. Arrows in the graph of urine volume indicate administration of $20 \mathrm{mg}$ furosemide. $S A O P$, Systolic aortic pressure; $S P A P$, systolic pulmonary arterial pressure; $C I$, cardiac index; $D O A$, dopamine; $D O B$, dobutamine.

cotomy for fear of injuring the right atrium, the wall of which was remarkably thinned. The mitral valve was replaced with a Björk-Shiley valve and the enlarged ring of the tricuspid valve was repaired with a Carpentier ring. The CPB time was 259 minutes, and the weaning process from CPB with the assistance of inotropic drugs was uncomplicated. The postoperative course was fairly stable in terms of hemodynamic parameters with optimal cardiac indices. Fig. 1 illustrates the events of the entire postoperative time course.

About 8 to 12 hours after operation the urine volume gradually decreased to 10 to $20 \mathrm{ml} / \mathrm{hr}$ despite intravenous injection of $20 \mathrm{mg}$ of furosemide. The creatinine level at that time was $1.4 \mathrm{mg} / \mathrm{dl}$. We then started intravenous infusion of synthetic human alpha-ANP (Carperitide; Suntory Inc., Division of Pharmaceuticals, Tokyo, Japan) at a rate of $0.05 \mu \mathrm{g} / \mathrm{kg}$ per minute. Thereafter, systolic and mean pulmonary arterial pressures decreased from 48 to
$33 \mathrm{~mm} \mathrm{Hg}$ and from 30 to $24 \mathrm{~mm} \mathrm{Hg}$, respectively, whereas systolic aortic pressure remained unchanged. The urine volume then dramatically increased to 100 to 120 $\mathrm{ml} / \mathrm{hr}$ and this volume was maintained at about that level for the next 90 hours until infusion of alpha-ANP was discontinued.

Successful extubation was accomplished 74 hours after operation. After cessation of alpha-ANP infusion, pulmonary arterial pressure increased again and urine volume decreased, suggesting that ANP was effective in this patient. Four weeks after operation, she received further alpha-ANP infusion at the same dosage for 4 days because of resistance to conventional diuretics. She recovered fully and was discharged from the hospital 3 months later. At that time, the plasma concentration of ANP was as before less than the detectable value.

Discussion. The special features of this case were marked enlargement of both the left and right atria and an 
extraordinarily low plasma ANP concentration. In general, the plasma ANP concentration shows a graded rise in patients with congestive heart failure because atrial distention is a key trigger that stimulates ANP secretion. ${ }^{2}$ This patient underwent closed and open mitral commissurotomy more than 30 years ago, at which time the appendages must have been removed or ligated. We previously reported that the secretory function of ANP was impaired after resection of atrial appendages in experimental heart failure models. ${ }^{3}$ In addition, sustained mitral stenosis and tricuspid regurgitation induced excessive extension of the atria, which may have further diminished the granules producing ANP. Thus it is considered that the patient had a lack of ANP secretion despite congestive heart failure.

Infusion of alpha-ANP was notably effective in this patient in terms of diuresis and in reducing preload level. Saito and associates ${ }^{l}$ first reported the beneficial effect of ANP administration in patients with congestive heart failure. We also reported the hemodynamic effects of ANP infusion after cardiac operation as cardiac output increased and pulmonary arterial pressure decreased. ${ }^{4}$ We recently performed a trial of continuous infusion of ANP for more than 24 hours in more than 10 patients after cardiac operation irrespective of the plasma ANP concentration. In selected patients, ANP infusion markedly increased urine volume whereas in these patients the diuretic effect of furosemide was minimal (unpublished data). Continuous infusion of alpha-ANP should be tried in patients after cardiac operations when oliguria develops.

\section{REFERENCES}

1. Saito Y, Nakao K, Nishimura K, et al. Clinical application of atrial natriuretic polypeptide in patients with congestive heart failure: beneficial effects on left ventricular function. Circulation 1987;76:115-24.

2. Bates ER, Shenker Y, Grekin RJ. The relationship between plasma levels of immunoreactive atrial natriuretic hormone and hemodynamic function in man. Circulation 1986;73:115561.

3. Nishimura K, Saito Y, Hidaka T, et al. Does atrial appendectomy aggravate secretory function of atrial natriuretic polypeptide? J Thorac Cardiovasc Surg 1991;101:502-8.

4. Nishimura K, Fujiwara Y, Okabayashi H, et al. Effects of administration of atrial natriuretic polypeptide in patients after cardiac surgery. J Jpn Cardiovasc Surg 1988;17:649-51.

\section{PYODERMA GANGRENOSUM AND MYELOFIBROSIS AFTER CORONARY ARTERY BYPASS GRAFTING}

Louis E. Samuels, MD, ${ }^{a}$ Marla S. Kaufman, BA, ${ }^{a}$ William G. Kussmaul, MD, ${ }^{b}$ and Stanley K. Brockman, MD, ${ }^{a}$ Philadelphia, $\mathrm{Pa}$.

A 66-year-old white man was admitted to the Allegheny University Hospitals, Hahnemann Division, Philadelphia, in April 1996 with unstable angina and shortness of breath. The medical history was significant for coronary artery disease, chronic renal failure, and hypertension. On admission to the hospital, the white blood cell count was 8100 per microliter, hemoglobin and hematocrit levels were $8.5 \mathrm{gm} / \mathrm{dl}$ and $25.1 \%$, and platelet count was 230 K/UL. Cardiac catheterization 2 days after hospital admission showed severe triple-vessel coronary artery dis-

From the Department of Cardiothoracic Surgery and the Department of Medicine, Division of Cardiology, ${ }^{b}$ Allegheny University Hospitals, Hahnemann Division, Philadelphia, Pa.

Received for publication August 26, 1996; accepted for publication Sept. 24, 1996.

Address for reprints: Louis E. Samuels, MD, Allegheny University Hospitals, Hahnemann Division, Broad and Vine Sts., MS 111, Philadelphia, PA 19102-1192.

J Thorac Cardiovasc Surg 1997;113:795-7

Copyright (C) 1997 by Mosby-Year Book, Inc.

$0022-5223 / 97 \$ 5.00+0 \quad \mathbf{1 2 / 5 4 / 7 8 1 7 7}$ ease. Seven days after hospital admission, the patient underwent coronary artery bypass grafting. The immediate postoperative course was uneventful.

On postoperative day (POD) 3 , fever $\left(101.7^{\circ} \mathrm{F}\right)$ and sternal tenderness with serous drainage developed. The white blood cell count was $15 \mathrm{~K} / \mathrm{UL}$. Empiric broad-spectrum antibiotic therapy was started. On POD 5, sternal wound debridement was done. No signs of gross infection were observed. Instead, there was extensive sternal and subcutaneous tissue necrosis. The operative Gram stain test showed negative results for organisms and there was no growth on culture. Skin and subcutaneous tissue necrosis progressed. On POD 6, an abrupt drop in the white blood cell and platelet counts occurred (Figs. 1 and 2). Fever and pancytopenia persisted over the next couple of days.

On POD 13, further sternal wound debridement was done. Similar findings of necrotic uninfected tissue were observed. On POD 19, histopathologic examination of the skin specimens was diagnostic of pyoderma gangrenosum. Steroid therapy (hydrocortisone $100 \mathrm{mg}$ intravenously every 8 hours) was instituted. On POD 28 , the patient underwent a bone marrow biopsy. Myelofibrosis was found. Therapy with bone marrow 